\title{
IS FLIPPED CLASSROOM ENOUGH? TEACHING SIMULATION USING IN-CLASS FLIP MODEL
}

\author{
Fahim Ahmed \\ Department of Management science \\ University of Strathclyde \\ Glasgow, G4 0QU \\ United Kingdom \\ Fahim.ahmed@starth.ac.uk
}

\begin{abstract}
The teaching of the simulation courses in Higher Education Institution (HEI) are mostly guided by the traditional method of lectures and lab tutorials. At some places, this style of teaching has been mixed with flipped-classroom where courses are delivered in the form of blended or distance learning environment. Despite advantages of the flipped-classroom, one of the key issue is the time students are expected to spend before the class. In our experience, students usually find it difficult to spend time preparing in advance of the class. We therefore propose to use a variant of flipped-classroom model called "in-class flip" for teaching simulation in HEI. A study with the second year undergraduate class on simulation is reported using in-class flip model and results are discussed. Initial findings from the experiment shows higher level of appreciation and satisfaction from the students compared to the traditional mode of teaching.
\end{abstract}

Keywords: In-class Flip, Flipped classroom, Simulation education, Higher Education Institution

\section{INTRODUCTION}

In this paper, we propose the adaptation of "in-class flip" model (Gonzalez, 2014) for teaching simulation in HEI which is a variant of the flipped-classroom model but significantly different in practice. To the best of our knowledge, the in-class flip model has not been used for teaching simulation (or similar courses) at HEI. We even struggle to find studies reporting its use in other broader disciplines within HEI. The key advantage of this model is that the students can learn at their own pace and within the class time which saves them from spending time on pre-class activities at home (which is a normal practice in a flipped classroom model).We present an experiment based on in-class flip model for a second year UG class and report the outcomes.

The contribution of this paper is to highlight the importance of in-class flip model that could bring a higher satisfaction and engagement level for students. In particular, this paper advocates significance of in-class flip model in teaching simulation (or courses containing similar structure) and also provides an opportunity to contribute further research in pedagogical innovations within HEI.

The rest of the paper is structured as follows:

Section 2: In-class flip vs flipped-classroom

Section 3: Adaptation of in-class flip model

Section 4: In-class flip model in practice

Section 5: Results from the experiment

Section 6: Conclusion and future work 


\section{Ahmed}

\section{IN-CLASS FLIP VS FLIPPED CLASSROOM}

The idea of the flipped classroom roughly dates back to 1990s when Harvard Professor Eric Mazur used this technique to ask students prepare in advance of attending the class (Mazur, 1997; Crouch and Mazur, 2001). He called his model "just in time" teaching. Salman Khan in TED talk (Khan, 2011) was probably the next most prominent work to have this approach gaining fame in recent times. Salman talks about the significant use of videos in his organisation, Khan Academy (Khan, 2019). Some other works around this time from (Bergmann and Sams, 2012) help this model to gain formal recognition and probably considered as the pioneering work in this area. Bergman and Sams were also the founder of flipped learning network among others (flippedlearning, 2019). There are several studies that discuss flipped classroom and it is hard to reflect on all this (see for e.g. Lage et al. ,2000; Chen et al., 2017; Lui et al., 2017; Schmidt and Ralph, 2016; DeLozier and Rhodes, 2017; KarabulutIlgu et al. , 2018)

The main requirement of this model expect students to prepare, read or reflect some material assigned to them in advance of the class. The teacher can then use this pre-class activity as a basis to develop an effective discussion in the class. The pre-class content does not need to be a video although video is generally considered to be the most important part of this model which students can watch in advance. The idea of any sort of visual enhancement (over text based illustration) has been shown to increase student learning in many early studies (Mayer and Gallini, 1990).

In all of the above work, there is some portion of self-study outside the classroom that students are expected to complete. We believe that with the changing life-style, work-life issues, and engagement with multiple roles, students find it difficult to spend any significant time outside their regular contact time in class. Our other argument is despite the flexibility for students to complete certain preparation before class, there is less motivation to complete them as no formal credit hours could be assigned to the amount of time they spent before the class. We report some studies here that evaluates the effectiveness of flipped classroom when teaching courses at HEI.

In one of the studies, Bergfjord and Heggernes (2016) reports that during the teaching of a management science course in a flipped-class room setting, most videos were watched before the exam rather than before the lectures. Amresh et al. (2013) used flipped-classroom for teaching computer science courses but reports on various pitfalls where how-to-do type videos were used. One of the findings was that the students find this method overwhelming (probably when learning unsupervised). As mentioned in Bergfjord and Heggernes (2016), technology can be a bottleneck to adapt this model especially when lecturers have to consider all possible technical aspects of students learning remotely including management of Virtual Learning Environment (VLE), internet, software support etc. Forsey et al. (2013) believe that flipped-classroom could devalue the significance of the lecture, organisation and the culture of the university. Some studies in engineering even mentioned that students had negative perceptions toward the course and felt unprepared for the exams because they had to manage their own learning. The final grades for traditional model of learning were even higher than a flipped-classroom in this study (Karabulut-Ilgu et al., 2018).

By no means we assert that this is an exhaustive list of evaluation of flipped class room model in HEI, but at least it gives the basis of our motivation for using in-class flip model. In our own experience, majority of students do not watch the pre-loaded videos on VLE and leave it till few days before the exam. This even takes more time to go through the content again and revise the topics of videos during the class time. One of the reason of less student engagement outside the class (especially when teaching simulation course) might be that student need a quick response to the query while they watch a video on various topics. In such cases, we feel that there is a need of supervised learning within the class time (to answer any prompt questions) rather than asking students to prepare the content before the class.

\subsection{In-class flip model}

The in-class flip model appeared over the internet few years back when Gonzalez (2014) wrote about this model of teaching in one of her blog at educational learning website (Edutopia, 2019). To the best of our knowledge, there is no prior work that introduces this variant of the flipped classroom. This model is shown in figure 1 where different works stations are introduced to be used in the class. 


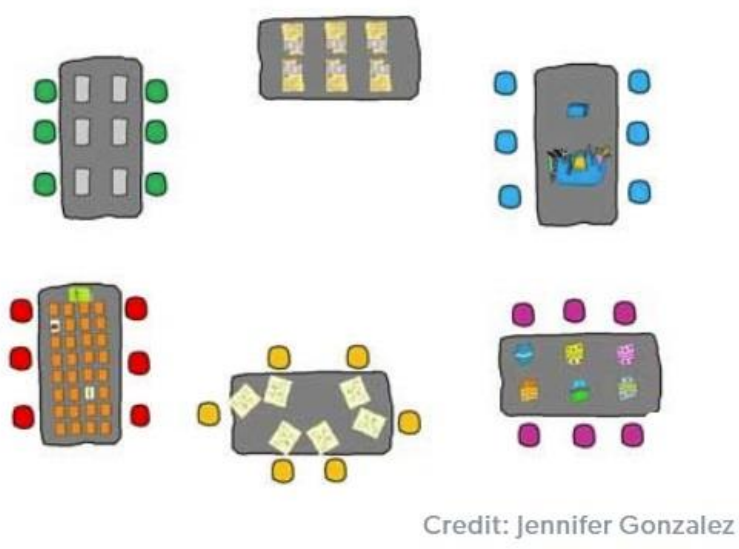

Figure 1: The in-class flip model (Gonzalez, 2014)

Each stations will have an activity assigned to it and a group of students will complete the activity on these stations in a pre-defined sequence. This means that students will need to keep revolving at different stations through the class time. Stations can have computer based activity (e.g. video, audio etc.) or a non-computer based activity (e.g. discussion, drawing, cards matching etc.) The teacher will be available most of the time supervising each student and answering any questions. Stations sequence are assigned in a way that students can start and progress with the activities on their own. The main station is where the video of the content is available to watch. This is recorded by the same teacher delivering that class (Gonzalez, 2014). Later on, Barnes and Gonzalez (2015) wrote about inclass flip where the idea of bringing the lecture part in the class room using different stations was used. Ramirez $(2017,2019)$ uses various station configurations adapted from Gonzalez (2014). Tucker (2016) used similar approach using station rotations. Ramirez (2018) used this model for teaching grade 7 English class.

\section{MODIFICATION OF IN-CLASS FLIP MODEL}

All of the above studies were proposed and demonstrated for school learning environment where the flexibility of moving groups of students over different station is manageable. Mostly, these works are based on the idea of various stations in the class (viewing station, independent station, feedback station, etc.) which requires students to move from one station to other in a pre-defined sequence (Gonzalez, 2014; Ramirez, 2018) .This setup makes it unsuitable for teaching in HEI where labs and lecture halls usually do not have that much capacity to create several rotating stations. Moreover, teaching of subjects like simulation is not similar to the teaching of history or language classes where activities can easily be planned for different stations (e.g. vocabulary exercise using flash cards etc.). In HEI teaching, the disruption from ever-rotating stations (students) would have significant effect on student experience as class teaching time for a particular subject is relatively small compare to school level teaching. 
To adapt this model for teaching large classes at higher education institute, we propose the idea of integrated-activity station in a computer based classrooms. This modification of in-class flip is shown in figure 2

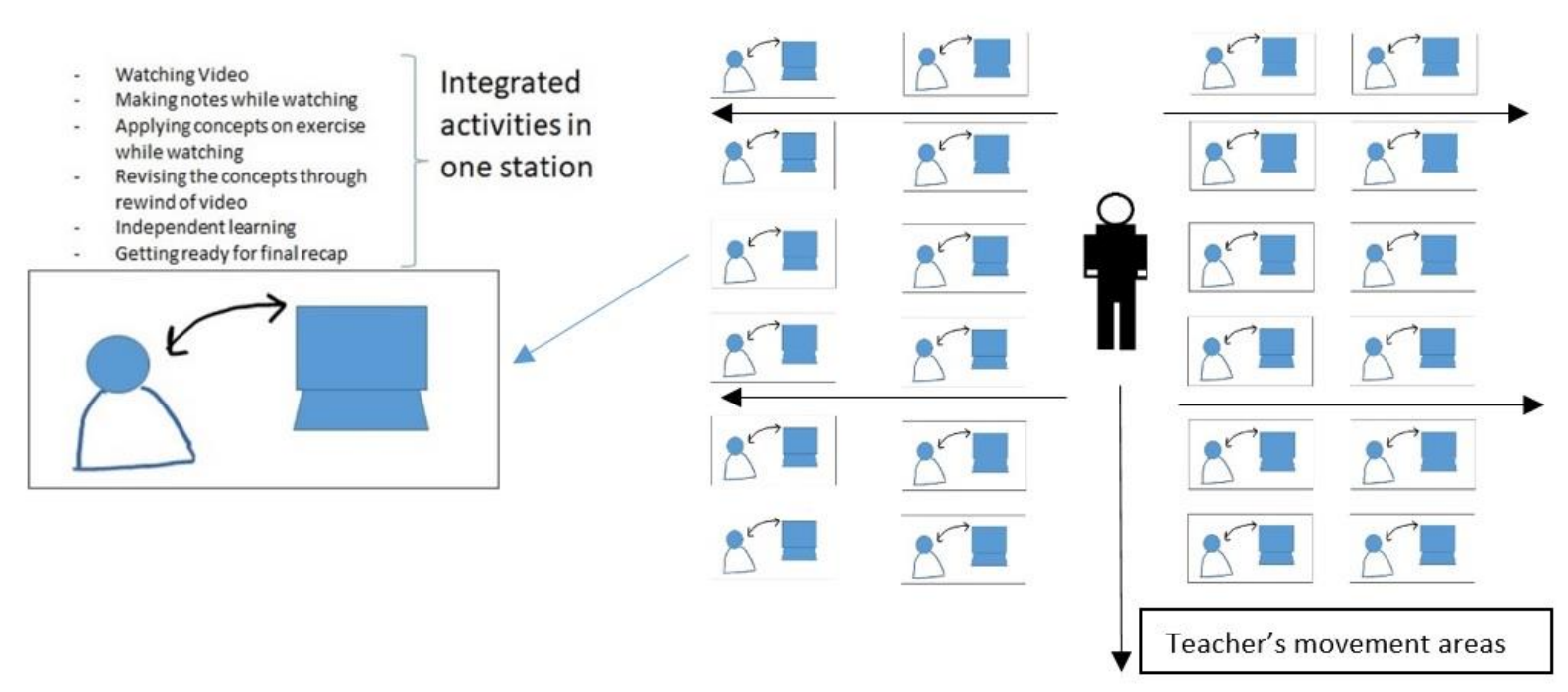

Figure 2: Modification of in-class flip model for teaching in HEI

In this model, students do all the activities at the same time (on individual basis) and do not revolve physically on different stations. All activities are integrated on single station and students are expected to cover them progressively (some sample activities are shown in figure 2). This helps to minimise the disruption in a large class and is perfectly suitable where individual learning needs to be enforced. A layout of such a classroom along with the teacher's movement area is also shown in figure 2. The activities are designed in such way that students are involved in a self-directed but supervised learning environment while teacher is available most of the time to answer any queries.

\section{IN-CLASS FLIP MODEL IN PRACTICE}

Next, we present the experiment of the modified in-class flip model conducted for second year UG simulation module. The simulation package used was Simul8. The course was conducted as a half semester module (part of a full module) at the department of management science, University of Strathclyde. Some background information is as follows:

Total number of students $=127$

International Students $=35$

Duration $=4$ Weeks

Topics Covered= Basics of simulation modelling, application of different concepts in Simul8, simulation model verification/validation, data modelling in Simul8, conceptual modelling

\subsection{Arrangements for the class}

A computer lab was booked on request for four hours per week spread over two days. All students were asked to bring their headphones and this instruction was re-iterated many times through class notice page and reminder messages the day before the class.

Videos for each topic were recorded in various small parts (3-8 mins) with some videos longer in length as continuation was necessary (10-12 mins). The style of the video recording was kept similar to the scenario as if students are listening to the live lecture. All video lectures were screen-recorded (with audio) as it was not necessary for lecturer to be present in the video. This also reduced the time 
and complexity of the videos required for recording. An exercise related to each sub-video was designed which students could attempt while watching the video or at the end of video (by going back and forth the important parts of the video). Students were expected to take notes while they watch the video and carry on the task assigned to them once they are ready to do so.

Lecturer was walking around in the class room, passing by the students throughout the entire time of video learning and during any individual exercise assigned to them (which lasts to around roughly an hour in total). During this time, lecturer answers any specific questions student may have (whether related to the content or any technical issue e.g. location of the video, sequence of the videos and exercise etc.). Students were expected to follow a complete lesson plan uploaded in advance on VLE before the class. A sample plan is shown in figure 3 .

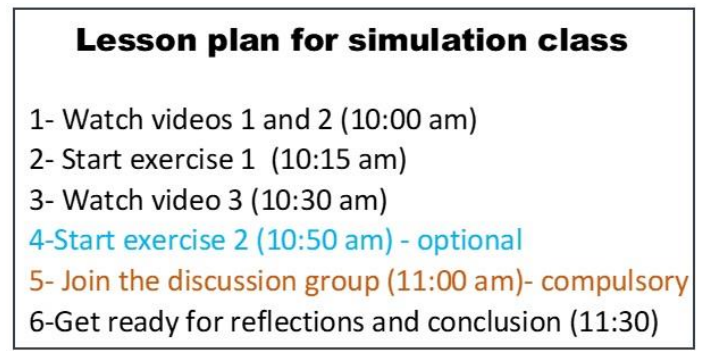

Figure 3: A two-hour lesson plan for teaching simulation with in-class flip model

It is important to understand the sequence of events in this plan. The first three steps are compulsory and students are expected to start them by the time indicated. However, keeping in view the different needs and learning pace of the individuals, some students would want to revise the video more than once in order to catch up with the rest of the class. To smooth out this variation, an optional activity was inserted after first three activities and only those students were expected to work with it who already have completed all the previous steps. The next activity (5) is again compulsory and requires everyone to join together in the form of a discussion group and complete the given task (this can be any formation of group; random, pre-assigned etc.). Those students who could not start on the optional activity also had to join the group work now. This creates an opportunity for every student to utilize their time effectively by not sitting and waiting for an activity to start (as fast learners can always do an optional activity in the middle). This optional activity needed to be designed in a way that it does not affect the balance of the class learning objectives and the group discussion. Finally, the lecturer sums up the class with important reflections and take away points from the session.

It is worth mentioning that in few instances, a large computer lab was not available and hence the students were split in two different labs and similar model was applied which ran smoothly without any disruption. This was possible as the only time where all students were needed together in one place was the conclusion or reflection part. As no station was required at this stage, students were asked to gather compactly in one place without acquiring one-to-one stations. The only requirement was that the two computer labs must not be booked too far from each other so lecturer could easily move between them. At times, a help from an extra tutor (usually postgraduate research student) was taken so one supervisor is present at all times with the students but the main lecturer was still supervising teaching in both rooms and was consulted anytime if required during his periodic rounds in both labs. 


\section{FINDINGS OF THE EXPERIMENT}

The results of experiment were recorded through questionnaire at the end of the course using paperpencil method (for a higher response rate). There were 102 students present at the time of questionnaire reporting. Three questions were asked from the students stated below:

Q1) Is this model better than the traditional lecture style?

Q2) Did this model increase your satisfaction level?

Q3) Any other comments/suggestions

The results are shown in figure $4 \mathrm{a}$ and $4 \mathrm{~b}$.
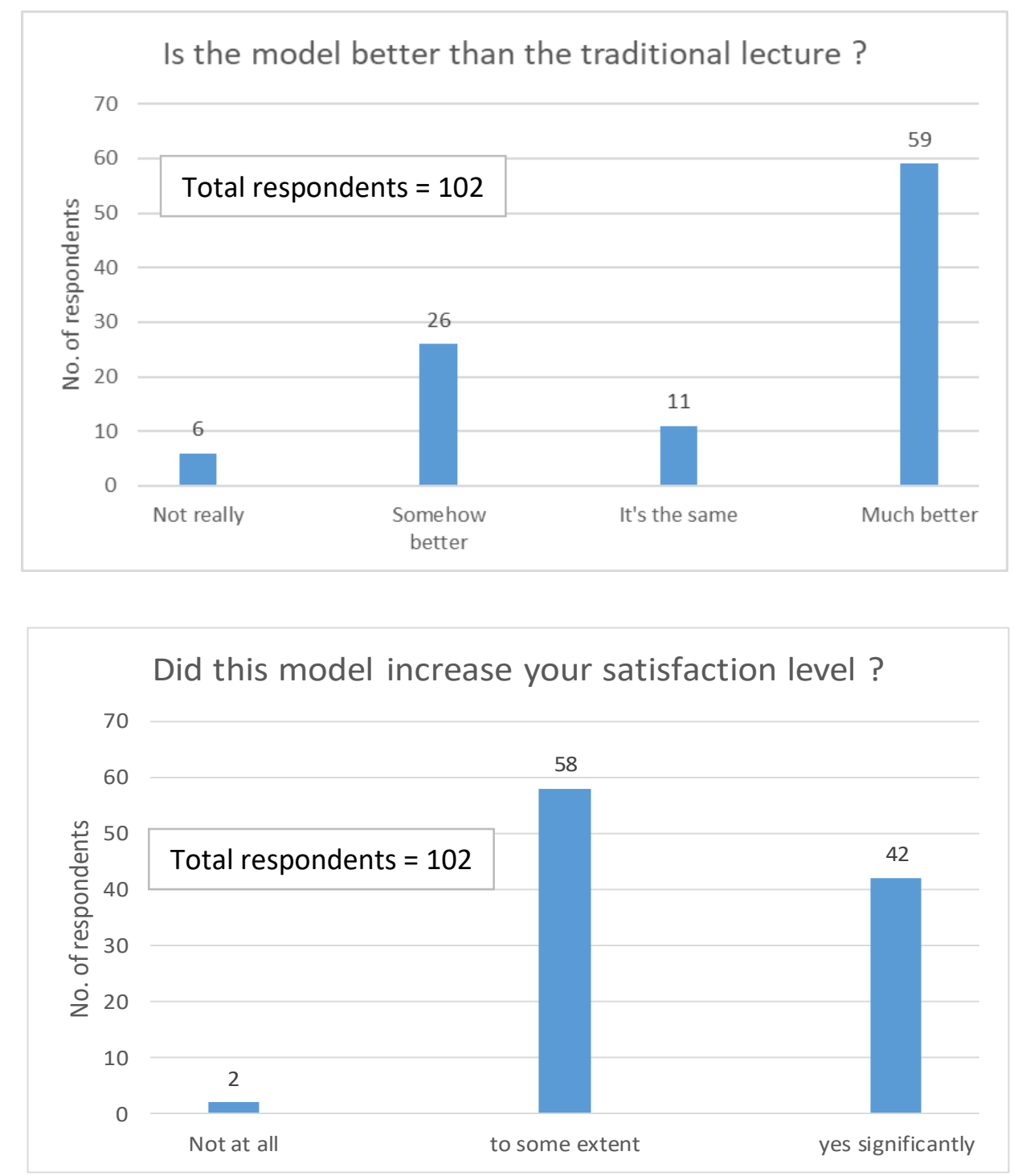

Figure 4a and 4b: Responses of the questionnaire for in-class flip experiment 
On the first question; 59 students responded in favour of this model while 26 students feel that this was better up to some extent. On the second question; 58 students felt that their satisfaction level has gone up to some extent while 42 students reported that this model has greatly increases their satisfaction level. Some interesting open-ended answers were noted and while we cannot share all responses due to limited space, we share snapshots of few critical ones in figure 5.

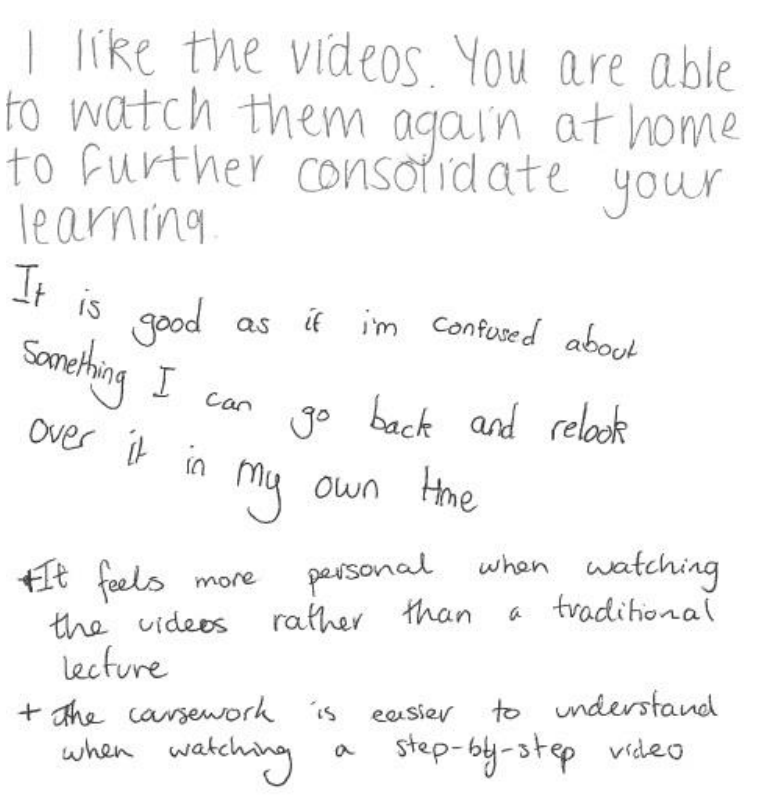

The method allowed me to wark@myoun pace but also have the guidance of the video's minork from hane aloo.

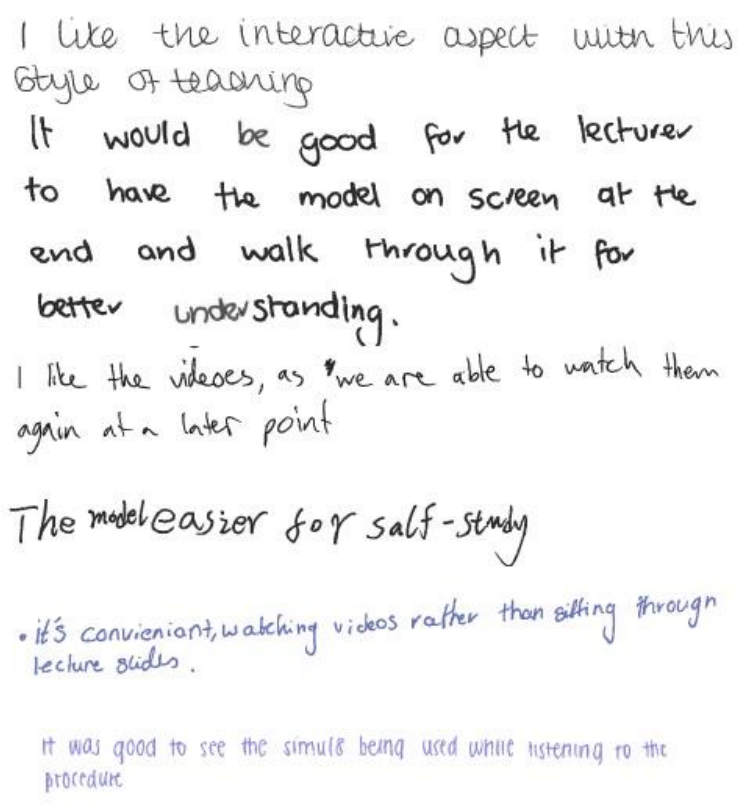

I like how you can sMip, pause, and rewind

as reeded. I thintt it causes less confusion.

Figure 5: sample of open-ended responses for in-class flip experiment

In total around $85 \%$ students reported that the model is better (significantly or to some extent) from the traditional lecture style teaching. Similarly, almost all student think that their satisfaction level has raised (either marginally or significantly) when learning through this model in the class.

\section{CONCLUSION AND FUTURE WORK}

In this study, we present an adaptation of in-class flip model to be used for teaching a simulation course at HEI. The initial results seems promising but there is a need of more detailed experiment on even larger classes (with different teaching facilities, various room layout, lecture rooms, available IT support etc.) to generalise the results. While there is clear appreciation of the model from majority of the students, it is hard to identify any relationship between acceptance level and satisfaction level of this model as these two responses might not be related strongly. For e.g., majority of the students see this model as "much better" but also think that their satisfaction level has only increased marginally. It would be interesting to investigate as what factors make this model appealing and what factors make this model more satisfying. Nevertheless, there is clear evidence of high inclination of students towards this model as witnessed by the results.

An additional advantage of this approach is shown to be an effective utilisation of the teaching resource where a lecturer can cover much broader area during the teaching (in some cases, two separate rooms) which would otherwise not be possible without either duplicating the class delivery or having another lecturer for the same teaching content. 
There are some obvious limitations of this model which needs to be addressed. Firstly, this model may not be suitable for teaching non-simulation type courses outside the lab environment where all students would not have access to PCs. There is a real challenge to ask students to bring their own laptops, smart phones and tablets within lecture halls. However, with the growing embedded technology within VLEs (like planetstream etc.) and high speed internet, students seem very comfortable in watching videos as it does not require heavy resources to download and play them. It would be interesting to see the results of such an experiment which is planned as a future work. Accessibility issues might need addressing (in few cases) by providing a transcript in advance to the special need students, so they are not left behind during the activities. Video captions and subtitles can also be used but all of this needs to be planned within the available time and resources. There is always a risk of technology going wrong (headphones or internet not working, students not registered on VLE etc.) and back up must be sorted out. Finally, to avoid students watching the video passively, more interactive element needs to be developed while they watch the videos using technologies like H5P, online multiple choice questions etc. and should be embedded within VLE.

\section{REFERENCES}

Amresh A., Carberry A R, \& Femiani J (2013, 2013). Evaluating the effectiveness of flipped classrooms for teaching CS1.

Barnes M D, \& Gonzalez J (2015). Hacking education: 10 quick fixes for every school: Times 10 Publications.

Bergfjord O J, \& Heggernes T (2016). Evaluation of a "flipped classroom" approach in management education. Journal of University Teaching \& Learning Practice, 13(5), 17.

Bergmann J, \& Sams A (2012). Flip your classroom: Reach every student in every class every day: International society for technology in education.

Chen F, Lui A M, \& Martinelli S M (2017). A systematic review of the effectiveness of flipped classrooms in medical education. Medical education, 51(6), 585-597.

Crouch C H, \& Mazur E (2001). Peer instruction: Ten years of experience and results. American journal of physics, 69(9), 970-977.

DeLozier S J, \& Rhodes M G (2017). Flipped classrooms: a review of key ideas and recommendations for practice. Educational psychology review, 29(1), 141-151.

Edutopia (2019) https://www.edutopia.org/topic/flipped-classroom accessed $10^{\text {th }}$ February 2020

Flippedlearning (2019) : https://flippedlearning.org/who-we-are/ accessed $21^{\text {st }}$ November 2019

Forsey M, Low M, \& Glance D (2013). Flipping the sociology classroom: Towards a practice of online pedagogy. Journal of Sociology, 49(4), 471-485.

Gonzalez J (2014). Modifying the flipped classroom: The" in-class" version. In: Edutopia. Retrieved from https://www.edutopia.org/blog/flipped-classroom-in-class-version-jennifer-gonzalez accessed 10 February 2020.

Karabulut-Ilgu A, Jaramillo Cherrez N, \& Jahren C T (2018). A systematic review of research on the flipped learning method in engineering education. British Journal of Educational Technology, 49(3), 398-411. doi:10.1111/bjet.12548

Khan (2019) (https://www.khanacademy.org/ accessed $21^{\text {st }}$ November 2019)

Khan, S. (Producer). (2011). Let's Use Video to Reinvent Education [Internet]

Lage M J, Platt G J, \& Treglia M (2000). Inverting the Classroom: A Gateway to Creating an Inclusive Learning Environment. The Journal of Economic Education, 31(1), 30-43. doi:10.1080/00220480009596759

Mayer R E, \& Gallini J K (1990). When is an illustration worth ten thousand words? Journal of educational psychology, 82(4), 715.

Mazur E (1997). Peer Instruction: A User's Manual. 1997 Upper Saddle River. NJ Instruction: A User's Manual Series in Educational Innovation.

Ramirez M (2017). What's an in-class flip? Retrieved from http://martharamirez.com.co/blog/whatsan-in-class-flip/ accessed $10^{\text {th }}$ February 2020.

Ramirez M (2018). In-Class Flip: Flipping a Literature Class for Student-Centered Learning. In Innovations in Flipping the Language Classroom (pp. 93-103): Springer. 
Ramirez M (2019). What's an in-class flip ? (revisited). Retrieved from https://flippedlearning.org/inflip/whats-an-in-class-flip-revisited/ accessed $10^{\text {th }}$ February 2020.

Schmidt S. M. P, \& Ralph D L (2016). The flipped classroom: A twist on teaching. Contemporary Issues in Education Research (CIER), 9(1), 1-6.

Tucker C (2016). The in-Class Flip : The Flipped Classroom meets the station rotation model Retrieved from https://catlintucker.com/2016/01/inclassflip/ accessed $10^{\text {th }}$ February 2020 .

\section{AUTHOR BIOGRAPHIES}

FAHIM AHMED is a teaching fellow at the department of Management Science, University of Strathclyde. His areas of expertise are mainly in Discrete Event Simulation and more broadly in the use of simulation methodologies within service operations. He attained his doctorate from Loughborough University, UK, in 2015. His PhD thesis was focused on the adaptation of computer science methodologies in simulation conceptual modelling. His current research includes pedagogical innovations within university teaching for OR and Management science courses.

https://www.strath.ac.uk/staff/ahmedfahimdr/ 